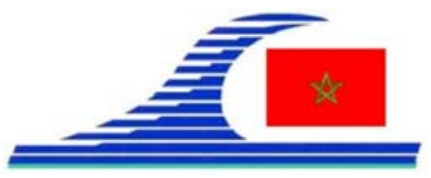

Conférence Méditerranéenne Côtière et Maritime

EDITION 2, TANGER, MAROC (2011)

Coastal and Maritime Mediterranean Conference

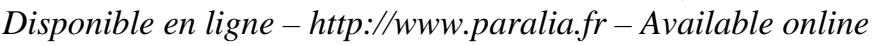

\title{
ARGUS imagery video technique for monitoring coasts
}

\author{
Christophe BRIERE ${ }^{1}$, Irv ELSHOFF ${ }^{1}$, \\ Robin MORELISSEN ${ }^{1}$, Giorgio SANTINELLI ${ }^{1}$
}

1. Deltares - WL | Delft Hydraulics,

Rotterdamseweg 185, P.O. Box 177, 2600 MH Delft, The Netherlands.

christophe.briere@deltares.nl

\begin{abstract}
:
Over the past 30 years, optical remote sensing has been developed into a very useful tool for sampling the nearshore environment. This tool is called the ARGUS system. The system depends on an understanding of the physics of the camera as an optical sensor and of the relationship of optical signals to the geophysical signals they represent (see HOLMAN and STANLEY (2007) for more details). This paper describes the applications of the ARGUS system with an emphasis on those relevant for monitoring the morphodynamics of the coasts.
\end{abstract}

Keywords:

ARGUS remote sensing - Shoreline detection - Bar dynamics - Wave and current

\section{Introduction}

Coastal managers aim for a sustainable development of a variety of coastal functions, including protection of the hinterland against flooding, swimmer safety, beach recreation and nature conservation. The design and evaluation of coastal policy measures and engineering interventions is hampered by the dynamics of the natural system. Effective decision making in this complex field thus demands the availability of detailed coastal state information with high resolution in time and space, at small scales of days to weeks and metres to kilometres. For example, along the Mediterranean Sea coast, the difficulty lies in the use of local beach nourishments and the demand for yearround exploitation of beaches, driven by the increasing recreational pressure on the coast. Remote sensing techniques, like the ARGUS video imagery technique, offer the potential of providing this information against low costs. An ARGUS-based monitoring system allows for enhanced opportunities for the monitoring of coastal systems, in order to serve for consultancy and research over a wide range of coastal zone management related issues (http://www.coastalwiki.org/coastalwiki/Argus_video_monitoring_system). 
La connaissance de la Mer :

un vecteur du développement durable en Méditerranée

\section{ARGUS capabilities}

The ARGUS system has been initially developed by the Coastal Imaging Lab (CIL) at Oregon State University (OSU; http://cil-www.coas.oregonstate.edu). An ARGUS station enables the controlled acquisition and return of optical remote sensing data from land-based computers observing coastal sites of interest. Physically, an ARGUS station consists of a number of video cameras attached to a host computer that serves both as system control and communication link between the cameras and central data archives. The so-called ARGUS Runtime Environment then makes accessible a robust set of technical capabilities, originally developed in a research environment (and to which Deltares - WL | Delft Hydraulics has contributed actively for the past 20 years), to allow non-research users to address different management problems. The sophisticated, operational video analysis methods enable nowadays e.g.:

a) quantification of shoreline evolution and beach width, to evaluate the potential for recreation or to assess the morphological impact of a storm event;

b) quantification of sediment volumes at the intertidal beach, to evaluate the morphological impact of coastal structures, to investigate seasonal fluctuations in beach dynamics and beach nourishments or to study the behaviour of morphological features such as sand spits and tidal flats near a harbour entrance;

c) quantification of sub-tidal beach bathymetry, to evaluate coastal safety, to assess the behaviour and performance of shore face nourishments;

d) assimilation (Beach-Wizard technique) of observations of wave breaking patterns and intertidal beach bathymetries within a numerical model, e.g. Delft3D or XBeach;

e) quantification of beach users, to establish daily, weekly, seasonal, and inter-annual user distribution patterns;

f) spatial quantification of an area covered by vegetation, to establish the seasonal dynamics of vegetation;

g) quantification of wave run-up, to evaluate the stability of coastal structures such as seawalls, harbour moles and revetments;

h) quantification of wave parameters (period, direction) and a longshore current characteristics (velocity), by sampling high frequency pixel signals from the video signals based on the intensity changes of these pixels

\section{Monitoring the coasts}

\subsection{Standard processing}

Standard post-processing of raw video data involves all routine activities that are necessary to enable a quantitative interpretation of the video data. The ARGUS system provides a standard environment to do so, called the ARGUS Runtime Environment.

The key component of this environment is the ARGUS database of meta-information on the video data. This database is filled after installation of a station and contains all 
information that is necessary for quantitative image interpretation (such as site and station characteristics, type of image processor, cameras and lenses, geometry solutions, meta-information on tides and waves, etc). This database is filled by Deltares (to ensure a unique embedding in the worldwide ARGUS network). Deltares also provides an initial set of geometry solutions. The Argus Runtime Environment can then be utilized to e.g. automatically rectify oblique video imagery at the actual tidal level in order to compose panoramic and plan view images of area of interest (figure 1).

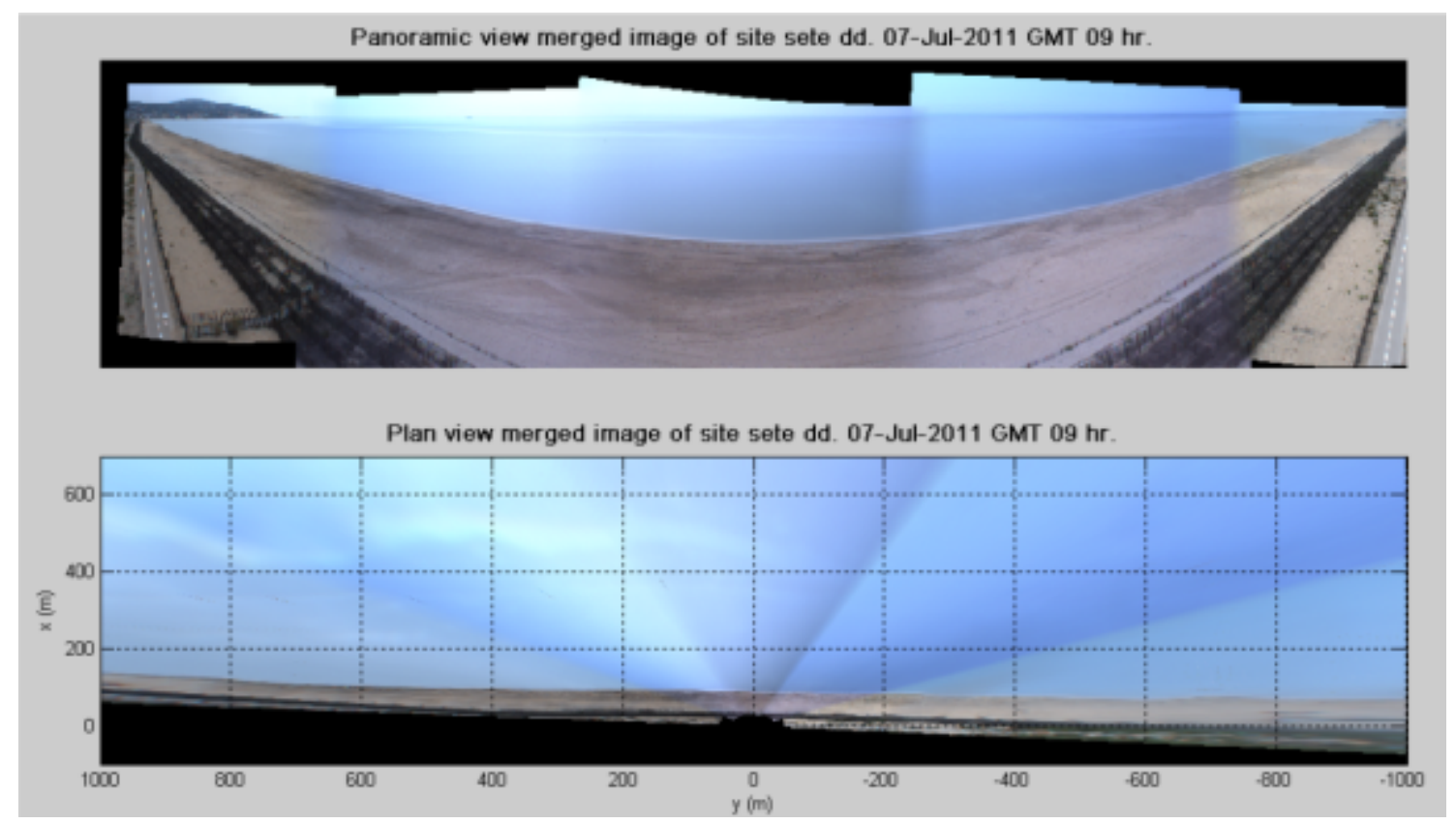

Figure 1. Panoramic and plan view merged images of the Sète site (France).

\subsection{Detection of the shoreline}

Routine analysis of the video data involves the mapping of three-dimensional shoreline co-ordinates from time-averaged video imagery and the concurrent hydrodynamic conditions. Our technique is based upon two independent sub-models (AARNINKHOF, 2003). The first identifies the location of the shoreline from time-averaged video images, based on colour differences between the wet and dry beach. This is achieved by the automated clustering of sub-aqueous and sub-aerial pixels in HSV ("Hue-SaturationValue") colour space, and applying an objective discriminator function to define their boundary (i.e. "shoreline") within a time-series of consecutive geo-referenced images. The second sub-model estimates the elevation corresponding to the detected shoreline features. This is done on the basis of concurrent tide and wave information, which is incorporated in a model that combines the effects of wave set-up and swash, at both incident and infragravity frequencies. 
La connaissance de la Mer :

un vecteur du développement durable en Méditerranée

\subsection{The bar dynamics}

The continuous high-intensity bands that are shown in the plan view merged images serve as a reasonable estimate for the submerged sandbars (LIPPMANN \& HOLMAN, 1989), and can be extracted from the images by the a longshore tracking of intensity maxima (VAN ENCKEVORT \& RUESSINK, 2001). A collection of tools enables the extraction and analysis of the visual features in ARGUS images of the nearshore zone. E.g. the toolbox provides an implementation of the Bar Line Intensity Mapper (BLIM) algorithm, which extracts horizontal high-intensity bands from ARGUS images. Several analysis and export functions are included in the toolbox.

\subsection{The quantification of wave and current parameters}

The ARGUS system provides the functionality to sample high frequency pixel signals from the video signals based on the intensity changes of these pixels. Indeed, besides snap shots and time-averaged video data, data sampling schemes can be designed as such to collect time series of image intensities, typically at $2 \mathrm{~Hz}$. Time series of pixel intensities can be sampled along a cross-shore or a longshore array. The resulting data collection, I(t,y;x), yields a time-stacked image. This pixel processing makes it possible to derive a number of physical field parameters, such as wave period and direction (not height) and a longshore currents from the video signal.

\section{Conclusions}

The ARGUS based monitoring system can be applied in the field of coastal zone management and coastal engineering in many ways. The system is cost-effective and can be run over long periods. Deltares has a license agreement with Oregon State University for the installation of ARGUS stations, but offers various services as well, from maintenance and standard data processing to dedicated image processing and analysis, and for consultancy or research. For more details, one may consult the page http://www.deltares.nl/en/product/810105/argus.

\section{References}

AARNINKHOF S.G.J. (2003). Nearshore Bathymetry Derived from Video Imagery. PhD Thesis Technical University of Delft, Delft. 175 p.

HOLMAN R.A., STANLEY J. (2007). The history and technical capabilities of Argus. Coastal Engineering, vol. 54, pp 477-491. doi:10.1016/j.coastaleng.2007.01.003

LIPPMANN T.C., HOLMAN R.A. (1989). Quantication of sand bar morphology: a video technique based on wave dissipation. Journal of Geophysical Research, vol. 94, pp 995-1011. doi:10.1029/JC094iC01p00995

VAN ENCKEVORT I.M.J., RUESSINK B.G. (2001). Effects of hydrodynamics and bathymetry on video estimates of nearshore sandbar position. Journal of Geophysical Research, vol. 106, pp 16969-16979. doi:10.1029/1999JC000167 